\title{
DETERMINANTS OF CONTRACEPTIVE USE IN WOMEN OF REPRODUCTIVE AGE IN 2016: SUSENAS DATA ANALYSIS
}

\author{
Yunita, Prastuti Soewondo, Taufik Hidayat \\ Masters Program in Public Health, Universitas Indonesia
}

\begin{abstract}
Background: As studies have shown, in 1997 (before decentralization), the contraceptive prevalence rate (CPR) was 57.4 percent and in 2007 (after decentralization) it was 61.4 percent. Over a ten-year period, the CPR has increased by only 4 percent. This suggests a relatively weak performance of the family planning program in Indonesia after decentralization, even though the knowledge of contraception is high among married women. This study aimed to determine the factors associated with contraceptive use among women in reproductive age in Indonesia using SUSENAS data 2016.

Subjects and Method: This was an analytic observational study with a crosssectional design. A sample of 190, 287 married women aged 15-49 years was selected by random sampling taken from SUSENAS data 2016. The dependent variable was contraceptive use. The independent variables were age, parity, nutritional status, education, marital status, living with husband, poverty, residence, health insurance status, distance to health facilities, and density of health personnel. The data were collected by the national socio-economic survey (SUSENAS), including some indices such as nutrient adequacy ratio standard, poverty line, and village potential. The data were analyzed by logit model.

Results: Contraceptive use increased with living with husband $(b=0.36 ; \mathrm{SE}=$ $0.02 ; \mathrm{p}<0.001)$, parity $(\mathrm{b}=0.07 ; \mathrm{SE}=0.01 ; \mathrm{p}<0.001)$, marital status $(\mathrm{b}=0.76$; $\mathrm{SE}=0.02 ; \mathrm{p}<0.001)$, nutritional status $(\mathrm{b}=0.02 ; \mathrm{SE}=0.01 ; \mathrm{p}<0.001)$, health personnel density $(b=0.72 ; \mathrm{SE}=0.01 ; \mathrm{p}<0.001)$, and distance to health center $(b=0.76 ; S E=0.01 ; p<0.001)$. Contraceptive use decreased with age $(b=-0.20$; $\mathrm{SE}=0.01 ; \mathrm{p}<0.001)$, health insurance ownership $(b=-0.27 ; \mathrm{SE}=0.02 ; \mathrm{p}<0.001)$, education $(b=-0.14 ; \mathrm{SE}=0.01 ; \mathrm{p}<0.001)$, poverty $(\mathrm{b}=-0.20 ; \mathrm{SE}=0.01 ; \mathrm{p}<$ $0.001)$, and residence $(\mathrm{b}=-0.121 ; \mathrm{SE}=0.01 ; \mathrm{p}<0.001)$.

Conclusion: Contraceptive use increases with living with husband, parity, marital status, nutritional status, health personnel density, and distance to health center. Contraceptive use decreases with age, health insurance ownership, education, poverty, and residence.
\end{abstract}

Keywords: family planning, contraceptive, participation, women

\section{Correspondence:}

Yunita. Masters Program in Public Health, Universitas Indonesia.

Email: yunita.phui@gmail.com. Mobile: +6285716667790.

Mid-International Conference in Public Health, Best Western Premiere Hotel, Solo, Indonesia, 18-19 April 2018 | 196 https://doi.org/10.26911/mid.icph.2018.03.32 